\title{
Bisphosphonates Zoledronate and Alendronate for the Management of Postmenopausal Osteoporosis
}

\author{
Israa Ahmed Radwan*, Nahed Sedky Korany, Bassant Adel Ezzat \\ Department of Oral Biology, Faculty of Oral and Dental Medicine, Cairo University, Cairo, Egypt \\ Email: *esraa.ahmed@dentistry.cu.edu.eg
}

How to cite this paper: Radwan, I.A., Korany, N.S. and Ezzat, B.A. (2018) Bisphosphonates Zoledronate and Alendronate for the Management of Postmenopausal Osteoporosis. Case Reports in Clinical Medicine, 7, 324-342.

https://doi.org/10.4236/crcm.2018.75030

Received: February 20, 2018

Accepted: May 7, 2018

Published: May 10, 2018

Copyright $\odot 2018$ by authors and Scientific Research Publishing Inc. This work is licensed under the Creative Commons Attribution International License (CC BY 4.0). http://creativecommons.org/licenses/by/4.0/

\begin{abstract}
Bisphosphonates are among the most frequently used antiresorptive drugs for the management of postmenopausal osteoporosis. We review here two of the commonly used bisphosphonates zoledronate and alendronate.
\end{abstract}

\section{Keywords}

Bisphosphonates, Alendronate, Zoledronate, Postmenopausal Osteoporosis

\section{Introduction}

Osteoporosis is a systemic disease that affects bone leading to reduced bone mass and degeneration of bone microarchitecture with subsequent increased bone fragility and high liability to bone fracture [1]. It has been appraised that more than 8.9 million osteoporotic fractures occur annually worldwide [2] and that osteoporosis affected nearly 53.6 million [54\%] geriatric patients in the United States in 2010 [3].

A valid classification of osteoporosis was established 25 years ago by Riggs \& Melton, 1986. They classified osteoporosis into primary osteoporosis, which includes type I postmenopausal osteoporosis and type II age related osteoporosis, and secondary osteoporosis [4].

Primary type I, postmenopausal osteoporosis mainly affects women who are three times more liable to osteoporosis than men [5] [6]. This is attributed to the postmenopausal estrogen depletion [7]. Estrogen can normally regulate bone mass and geometry [8], through decreasing receptor activator of nuclear factor kabba beta ligand [RANKL] and increasing osteoprotegerin [OPG] expression in osteoblasts, thus reducing osteoclast differentiation [9]. Meanwhile, following 
menopause and oophorectomy, bone turn over increases by $50 \%$ - 100\% [10] [11], as estrogen depletion can enhance osteoclast activation by upregulating RANKL expression in addition to increasing pro-inflammatory cytokines as interleukins 1 and 6 and tumor necrosis factor alpha [12]. Men on the other hand, are not subjected to dramatic sex hormones depletion as women and therefore, they are less predisposed to develop primary type I osteoporosis. Instead they are more commonly affected by primary type II osteoporosis, and secondary osteoporosis [13]. Primary type II osteoporosis is age related and affects patients above 70 years of both sexes, with progressive thinning of both cortical and spongy bone [4].

Secondary osteoporosis, contrariwise, affects patients of younger age category [14]. It is caused by several underlying diseases that may either disturb calcium homeostasis or bone metabolism, as hypogonadism in men, Cushing's syndrome, hypercalciuria, hyperthyroidism, hyperparathyroidism, celiac disease, or other malabsorption syndromes, gastrointestinal surgeries or disorders, diabetes mellitus type 1, alcoholism, hemochromatosis, hyperprolactinemia and multiple myeloma [15]. It can also be a result of wide varieties of medication as glucocorticoids, gonadotropin-releasing hormone analogues, androgen receptor blockers, neuroleptic dopamine antagonists, enzyme-inducing anticonvulsants, thiazolidinediones, proton pump inhibitors, antineoplastics and antidepressants [13].

\section{Treatment of Osteoporosis}

Pharmacological therapies of osteoporosis should be able to target trabecular as well as cortical bones, which is reflected clinically as decreased risk of vertebral and non-vertebral, appendicular skeleton fractures [16].

Pharmacological options for the management of osteoporosis can be broadly classified according to the mechanism of action into anti-resorpative medications, which inhibits bone resorption, such as bisphosphonates, hormone replacement therapy, suppressors of RANK-L [denosumab], selective estrogen receptor modulators, calcitonin, anabolic agents, which promotes bone formation as parathyroid hormone (parathyroid hormone 1-84, parathyroid hormone 1-34), strontium ranelate and combination therapy [17] [18]. In the current review, the antiresorptive bisphosphonates zoledronate and alendronate will be reviewed.

\section{Bisphosphonates [Bps]}

Bps are the most commonly prescribed anti resorpative medications for the management of osteoporosis. They are characterized by chemical structure containing 2 phosphate groups, hence their name. Where, they have a core of phosphate-carbon-phosphate atoms [P-C-P bond] and two R side-chains [19] [20].

Bps' family includes non-nitrogen bisphosphonates, which are the earliest 
synthetized Bps, and nitrogen Bps [N-Bps]. For osteoporosis treatment, N-Bps, containing $\mathrm{N}$ group in the $\mathrm{R}$ side chain, including alendronate, ibandronate, risedronate \& zoledronate, are now more commonly used [21] [22]

Bps are successfully used for the management of several bone diseases owing to its ability to suppress bone remodeling, as Paget's disease, myositis ossificans, progressive osteoporosis, drug-induced bone loss, heterotopic ossification, primary hyperparathyroidism, fibrous dysplasia \& multiple myeloma [23]. Bps can also be used to reduce bone metastases associated skeletal complications, hypercalcemia of malignancy \& for the treatment of osteogenesis imperfecta [24].

\section{Pharmacology of bisphosphonates}

Bps can be administered orally or through intra venous injection. However, about $1 \%-3 \%$ of oral dosage is absorbed [25]. Oral bioavailability is influenced by presence of food, magnesium or calcium in stomach [26]. Other routes of administration as subcutaneous injection can lead to local toxic effects [27]. 60\% of Bps within the circulation become attached to bone calcium-phosphorus surface, while the remaining $40 \%$ are excreted by the kidney [20] [28].

Bps can preferentially attach to the hydroxyl apatite [HA] exposed at sites of active bone resorption allowing a high selective binding to skeletal system, especially areas with active bone resorption via $\mathrm{P}-\mathrm{C}-\mathrm{P}$ structure of Bps, resulting in targeted attachment to areas with bone resorption [29]. Bps which become incorporated within the bone are released during subsequent bone remodeling, and it is fated to be internalized by the osteoclasts, reattached to the bone HA or it may pass to the blood stream where it may either become excreted by the kidney, or reattached to different skeletal site to be recycled [30] [31].

Therefore, skeletal elimination of Bps depends on bone remodeling and the affinity of the bisphosphonate to bind to bone surface. This can account for the slow release and elimination of Bps, its long life time, and subsequently, extended inter dosage durations. Bisphosphonate with the greatest affinity for bone surface is N-Bps as zoledronic acid [ZOL], which can be given once yearly, and Bps with the lowest affinity are non-nitrogen Bps as etidronate \& clodronate [28] [32].

Mode of action of Bps: [Figure 1]

Bps affect bone remodeling by two separate mechanisms a physiochemical one, which is the earliest described mode of action, and a cellular one [23]. One of the earliest experiments, done to elucidate the mechanism of action of Bps was done by Russell, Muhlbauer, Bisaz, Williams, \& Fleisch, 1970. They established that Bps can decrease the dissolution of $\mathrm{HA}$ in vitro, and therefore, the binding of Bps to HA crystals of the bone can directly decrease the bone resorption by reducing the crystals solubility [33].

Bps can also affect bone remodeling on cellular level. Where, their affinity to HA bring them in intimate contact with bone cells' extracellular space [34]. Bone cells are exposed to the drug upon administration or upon the release of Bps from bone HA during osteoclastic bone resorption. As a result, Bps become internalized by bone cells, particularly osteoclast, and therefore they are able to 


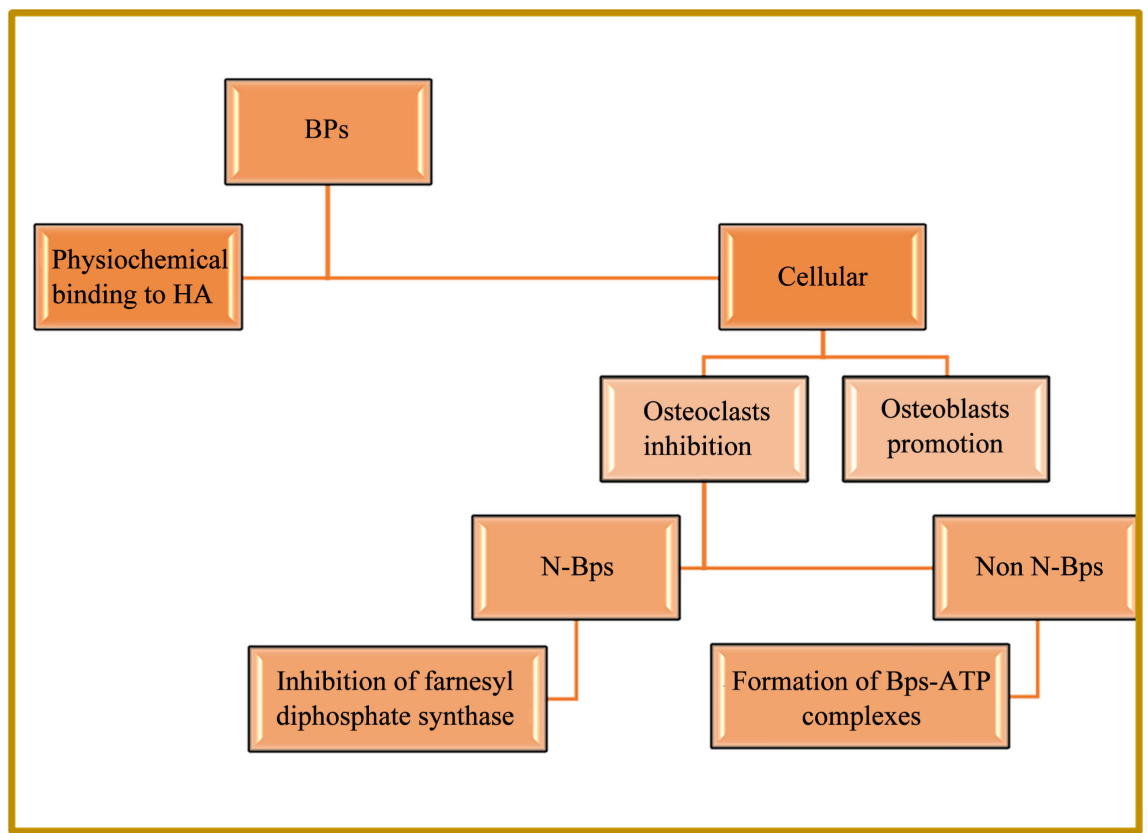

Figure 1. Mechanism of action of bisphosphonates.

exert their intracellular influence [35]. They can affect both osteoclast [36], and osteoblast cell action [37].

Once Bps become internalized intracellularly, their effect on osteoclast is dependent on the structure of the " $R$ " side chains [36]. Non nitrogen containing Bps such as etidronate, can bind to intracellular adenosine triphosphate [ATP] molecules forming insoluble complexes, which decrease ATP intracellular availability, resulting in alteration of many cellular functions and activities that are dependent on this molecule. This eventually results in cytotoxic alteration in cell function and cell death [38]. Moreover, intracellular accumulation of Bps-ATP complexes results in direct cellular cytotoxicity and death [39].

$\mathrm{N}$-Bps have a dissimilar intracellular mechanism of action. Where N-Bps cause disorganization of osteoclast cytoskeleton, affect osteoclast morphology, hinder the formation of ruffled border and prevents the formation of resorpative pits in vitro [40] and prevent intracellular transport of lysosomal enzymes to the basolateral surface of the cell, which is the normal site for their release against resorbing bone surface [41].

Where, N-Bps can interfere with the intracellular mevalonate pathway, through inhibition of enzymes as farnesyl diphosphate synthase. Consequently blocking the production of farnesyl diphosphate which impede the prenylation of guanosine tri phosphatases [GTpases] [42] [43]. Prenylated GTpases are important signaling molecules involved in cytoskeleton organization of osteoclast and subsequently, can modulate osteoclast functions such as formation of ruffled border, intracellular transport of vesicles as lysosomes and formation of actin ring [44]. The inhibition of prenylated GTpases by Bps was reviewed by Rogers et al., 2011 [28]. This effect is dose related [45]. 
The influence of Bps on bone homeostasis and bone remodelling doesn't only rely on osteoclast inhibition, but it can also affect osteoblast homeostasis [37]. Bps can protect bone cells from apoptosis in vitro in osteoblastic and osteocytes murine cell line [46], in human osteoblasts cell line [47], and in vivo in mice [48]. However, it was deduced that the anti resorpative effect of Bps is more potent as compared to the anti-apoptotic effect they have on osteoblast [48].

Bps can influence osteoblast differentiation and alkaline phosphatase activity in vitro as well [49] [50]. The effect of Bps on osteoblast in vitro is dose related, with inductive influences noticed at low dosages $10^{-9} \mathrm{M}$ to $10^{-6} \mathrm{M}$, \& inhibitory influences found at dosage higher than $10^{-5} \mathrm{M}$ [37].

Moreover, Bps can diminish the instructive influence of osteoblast on osteoclastic cells differentiation. Osteoblasts subjected to Bps showed an inhibitory effect on differentiation of osteoclast precursor cells [51]. Where, Bps can down regulate osteoblast expression of RANKL and upregulate their expression of OPG [52] [53], which are key regulators of osteoclast differentiation [54]. Therefore, Bps inhibitory effect on bone resorption is augmented by its ability to induce osteoblast to interfere with the osteoclasts differentiation and survival [37].

\section{Bisphosphonates side effects:}

Bps are considered as a safe drugs with its benefits exceeding any possible risks [24]. Bps related osteonecrosis of the jaw is considered as one of the most serious adverse effects of Bps. As defined by the American Society for Bone and Mineral Research "Bps related osteonecrosis of the jaw is an area of exposed bone in the maxillofacial area that does not resolve within eight weeks after diagnosis, in a patient on Bps treatment, and with no history of radio therapy to the area" [55].

Bps related osteonecrosis of the jaw more commonly affect the mandible [65\%] than the maxilla [28.4\%] or other locations [0.1\%], and more likely to affect sites with thin covering mucosa [56]. The severity and the clinical picture usually ranges from an extraction socket which fails to heal, to a large area of exposed necrotic bone in the jaw [57]. It may even be asymptomatic and undiagnosed until triggered by trauma to the jaw area which may be mechanical trauma, extensive dental procedure, as dental extraction, periodontal disease or infection to the jaw area [58].

The risk of developing Bps related osteonecrosis of the jaw is dose and time dependant with high risk in case of intra venous administration of high doses for a extended durations [59]. Oncological doses of Bps, used in case of malignant bone metastasis, are considered as high risk factor for developing Bps related osteonecrosis of the jaw [60]. Where, incidence of Bps related osteonecrosis of the jaw among oncology patients ranges from $0 \%-0.186 \%$ [61], and the incidence is approximately $10 \%$ in patients with myeloma. However, the incidence of Bps related osteonecrosis in patients receiving therapeutic doses for osteoporosis treatment is relatively low. It ranges from $0 \%$ to $0.04 \%$ [55]. 
Pathogenesis of Bps related osteonecrosis of the jaw is related to the inhibitory effect of Bps on bone remodelling. Where, presence of local infection or even accumulation of micro cracks within the bone, coupled with the inactivated osteoclast and inadequate bone repairing mechanism can result in bone necrosis [62].

Bps have also been linked to atypical femur fracture [63]. Mashiba et al., 2001 observed that Bps associated inhibition of osteoclast activity and bone remodelling in beagle dogs, results in accumulation of micro-damage with reduction in bone toughness by about 20\% [64]. Suppression of bone remodelling by Bps by $40 \%$ can lead to micro cracks accumulation with the bone [65]. Accumulation of micro damage with no adequate repairing mechanism may, eventually, result in fatigue fracture of areas of the bone with high tensional stresses such as proximal part of the femoral shaft [63].

Regardless, Miller and Watts, 2013, endorsed therapeutic use and benefits of Bps. They concluded that the gains of Bps therapy outweigh any possible treatment associated complications [23].

\section{Alendronic Acid [Alendronate]}

Alendronic acid is a N-Bps with a higher binding affinity to hydroxyapatite of bone as compared to ibandronate, risedronate or etidronate which accounts for the higher potency and skeletal retention of alendronate [66]. Chemical structure of alendronate is shown in Figure 2. Alendronate, for the treatment of osteoporosis is usually administered as a weekly oral dosage of $70 \mathrm{mg}$ [67].

However, oral administration is associated with increased risk of inadequate absorption from the gastrointestinal tract, and increased risk of the tablet adhering to the oesophageal wall upon intake which mandates special precautions where, patient should be advised to take alendronate on an empty stomach with a large glass of water and wait for at least 30 minutes before any food intake to assure proper absorption of the drug. Moreover, patient should remain upright for half an hour to prevent the tablet from sticking in the oesophageal wall which might lead to oesophageal ulceration [68] [69].

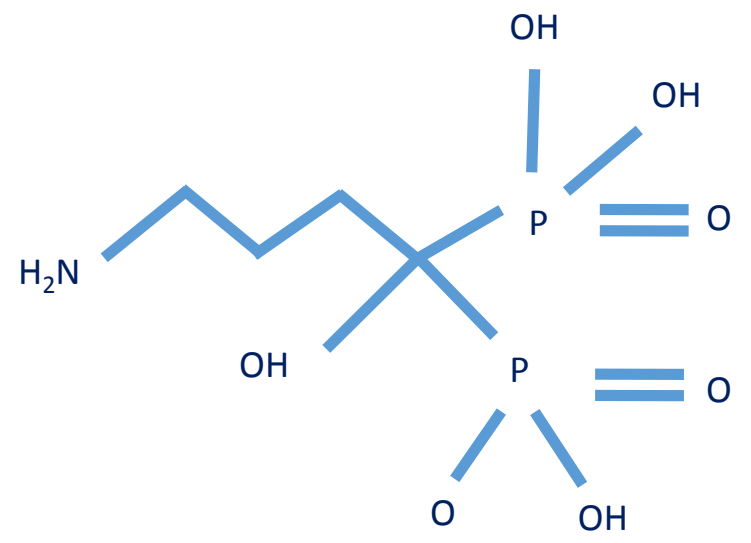

Figure 2. Chemical structure of alendronate. 


\section{Efficacy of Alendronic acid:}

In 1993, a randomized, double blinded, controlled clinical trial, the fracture intervention trial was laid out by Black et al., 1993 [70]. 6457 osteoporotic women were recruited and divided into two sub-studies according to the presence [ $n=2023$ women] or absence of previous vertebral fractures [ $n=4434]$. Women with previous vertebral fractures were allocated in the vertebral fracture sub-study and followed up for an average of 2.9 years [71], while women without vertebral fractures were allocated to the clinical fracture sub-study and were followed up for average of 4.2 years [72]. Women in both sub-studies were randomly allocated to receive alendronate at daily dosage of $5 \mathrm{mg} /$ day for 2 years followed by $10 \mathrm{mg} /$ day for the remaining study duration or placebo. Ensuing the follow up period, it was concluded that alendronate was effective in decreasing the risk of vertebral fractures in osteoporotic women with previous one or more vertebral fractures [71] or without prior vertebral fractures [72] as compared to the placebo control group. Further analysis of the data collected from 3658 osteoporotic patients, previously recruited in the fracture intervention trial demonstrated that in addition to reducing risk of vertebral fractures, alendronate was also effective in reducing non-vertebral fractures [73]. Moreover, bone mineral density [BMD] was measured for 2984 women recruited in the fracture intervention trial at baseline, one year and at 2 years. The lowest frequency of new vertebral fractures was observed in patients with $3 \%$ or more increases in BMD during the first 1 or 2 years of alendronate therapy [74].

In an extension to the fracture intervention trial, 1099 women previously recruited through the fracture intervention trial were randomly assigned to receive a dose of $5 \mathrm{mg}$ or $10 \mathrm{mg}$ alendronate or placebo daily for additional 5 years. It was recommended to discontinue alendronate administration after 5 years, except in women with increased risk of vertebral fractures [75].

10 years randomized, controlled, clinical trial was conducted enrolling 994 postmenopausal women with osteoporosis. Patients were randomly assigned to receive alendronate at daily dosage of $5 \mathrm{mg}$ or $10 \mathrm{mg}$ for 3 years, or $20 \mathrm{mg}$ for 2 years followed by $5 \mathrm{mg}$ for the remaining year or placebo. Patients were followed up for three years within the main trial, Alendronate was found to be safe, well tolerated [76], effective in increasing the bone density and reducing the liability to vertebral fractures [77]. This was followed by 2 years follow up in the first extension [78]. A second extension was held where alendronate was administered for additional 2 years [79]. Finally, this was followed by a third extension of the same study where alendronate was administered for extra 3 years which sums up 10 years of alendronate administration [80]. It was finally concluded that daily administration of alendronate in osteoporotic women, can restore bone mineral density, and decrease the risk of vertebral fracture and deformity. The authors were against the discontinuation of the drug, as cessation of its use, was associated with gradual loss of its effect.

A meta-analysis held out by Cranney et al., 2002 concluded that alendronate 
treatment is associated with increased BMD and reduced the incidence of vertebral fracture in post-menopausal osteoporotic women. It was also associated with reducing non-vertebral fractures in patients without established fractures [81]. Similarly Papapoulos, Quandt, Liberman, Hochberg, \& Thompson, 2005 deduced, through a meta-analysis, that alendronate is associated with decreased frequency of hip fracture [82].

\section{Side effects of Alendronic acid:}

Common side effects of alendronate include indigestion and epigastric pain which has been estimated to affect about 5 percent of patients upon alendronate intake. Moreover, improper administration of the drug might be associated with adherence of the tablet to the oesophageal wall which might be accompanied with oesophageal ulcerations [69].

Bps related osteonecrosis of the jaw is a rare occurrence, associated with alendronate administration, which has been estimated to affect less than 0.004 percent of patients on oral dosage of alendronate for the management of postmenopausal osteoporosis per year [83]. Atypical femur fractures are also a rare side effect of alendronic acid which affects about 5 cases per 10,000 patient on alendronate for the management of osteoporosis per year [84].

\section{Zoledronic Acid [ZOL]}

ZOL is a third generation, N-Bps. It has higher binding affinity to bone when compared to alendronate, ibandronate and etidronate and consequently have the highest skeletal retention [66]. The binding affinity of Bps to hydroxyl apatite of the bone directly reflects on its potency where, Bps with high affinity to hydroxyapatite, such as ZOL, are the most potent [85]. Chemical structure of zoledronic acid is demonstrated in Figure 3.

ZOL was found to be one of the most potent Bps with very strong ability to inhibit farnesyl diphosphate synthase enzyme and a strong ability to inhibit osteoclast function. Dunford et al., 2001 observed that ZOL \& minodronate are the most potent inhibitors of the enzyme farnesyl diphosphate synthase, in cell-free enzyme extracts and in osteoclasts cell culture in vitro followed by risedronate, ibandronate, incadronate, alendronate and finally pamidronate [43]. The authors

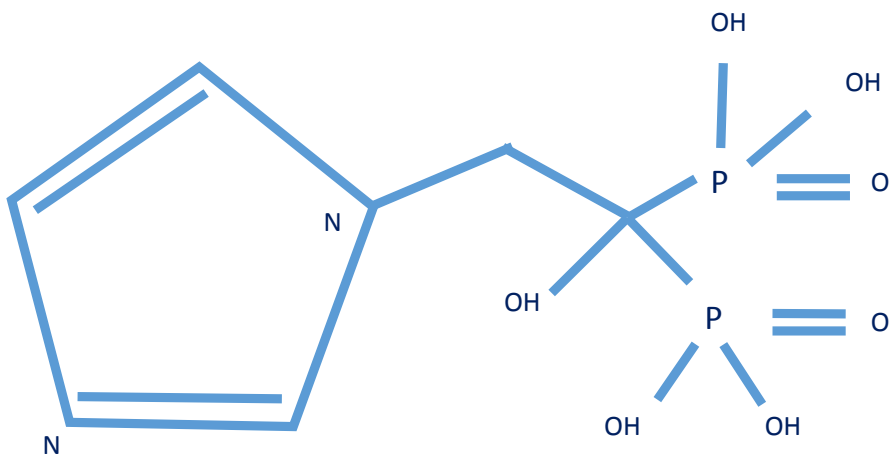

Figure 3. Chemical structure of ZOL. 
correlated between the inhibitory effect of N-Bps on the enzyme farnesyl diphosphate synthase and its effectiveness on bone resorption inhibition in vivo. ZOL was shown to be 10 times more effective in preventing bone loss in ovariectomised rats than alendronate [86].

$\mathrm{ZOL}$ is usually administered as a yearly intravenous injection of $5 \mathrm{mg}$ [68]. Authors concur that the yearly dosage of ZOL is more convenient, and patients are more likely to adhere to it, as compared to the more frequent dosage of oral Bps [87] [88].

\section{Efficacy of ZOL:}

Black et al., 2007 conducted a double-blind, placebo-controlled trial, recruiting 7765 postmenopausal women with diagnosed osteoporosis through the pivotal fracture trial, to study the effect of ZOL on fracture risk reduction [88]. The patients received a yearly intravenous injection of $5 \mathrm{mg} \mathrm{ZOL}$ or placebo for 3 years. It was deduced that yearly intravenous injection of $5 \mathrm{mg} \mathrm{ZOL}$ for a 3-year period can significantly reduce the fracture risk of vertebral, hip bone, and other sites as compared to placebo group. Furthermore, bone biopsies, were acquired from 152 patients from the pivotal fracture trial, at a time between 33 to 36 months. ZOL was able to decrease bone turnover by $63 \%$ and decrease active remodelling sites of bone and preserve bone micro-structure [89].

Bone turn over markers were also measured in samples from a subgroup of patients of the former mentioned study. It was observed that yearly intravenous injection of ZOL lead to significant reduction in bone turn over markers, indicating a decrease in bone remodelling. This can explain the decreased fracture risk associated with the ZOL treatment [90].

Aiming to determine the adequate duration of ZOL treatment required to reduce fracture risk associated with postmenopausal osteoporosis, a randomized controlled extension of the pivotal fracture trial, was conducted to study the long term effect of ZOL by Black et al., 2012 [91]. This study included 1233 postmenopausal women, previously allocated to the ZOL group in the main study, who formerly received ZOL for three years. They were randomized to either ZOL group, to receive ZOL yearly for additional 3 years or to placebo group. Bone density and turn over markers of patients within the ZOL group, showed an insignificant difference when compared to those of placebo group's patients. This indicates a sustained effect of ZOL for 3 years after discontinuation of the treatment. The authors suggest a 3 years off treatment following 3 years on treatment. Similar recommendations were given by [92].

Second extension of the same study was carried out by Black et al., 2015. 190 women, who previously received ZOL for the duration of 6 years in the first extension, were randomly allotted to ZOL group, to receive intravenous injection yearly for additional 3 years [which sums up to a total of 9 years of treatment] or placebo group. They observed an insignificant difference in bone turn over markers, bone mineral density and fracture risk between placebo and ZOL groups. Also a non-significant increase in cardiac arrhythmia between the par- 
ticipants was noticed. A discontinuation of the ZOL treatment for 3 years after 6 years of therapy was recommended [93].

The sustained effect of a single dosage of ZOL was studied by Grey et al., 2009 and Grey et al., 2010. They recruited 50 postmenopausal women with osteopenia through a double-blind, randomized, controlled trial to receive a single dose of $50 \mathrm{mg}$ intravenous ZOL or placebo. Bone turnover markers and bone mineral density were measured at 12 months and 2 years and at 3 years. Both consecutive studies demonstrated that a single dose of ZOL has a sustained effect on reducing bone turn over, and therefore, maintaining bone mass for up to three years, as compared to the placebo group [87] [94].

Similar results were reported by Greenspan, Perera, Ferchak, Nace, \& Resnick, 2015. They conducted a 2 years, randomized, controlled, double blinded study, including 181 postmenopausal osteoporotic women. BMD was measured at 12 months and 2 years. They concluded that a single dose of ZOL can prevent osteoporosis associated deterioration in BMD, for 2 years [95].

ZOL was also effective in decreasing the liability to fracture in men with osteoporosis [96], and increasing bone mineral density in patients with glucocorticoid induced osteoporosis [97]. Moreover, administration of $4 \mathrm{mg}$ ZOL every 3 or 4 weeks, used in addition to antitumor therapy, can control hypercalcemia and skeletal complications associated with bone metastases secondary to malignant tumours as multiple myeloma or malignancies of breast or prostate [98]. ZOL has also been found to have antiangiogenic properties in vivo, which can further endorse its use alongside antitumor drugs [99]. Table 1 offers a summary for the efficacy and clinical usage of zoledronate and alendronate.

Side effects of ZOL:

$\mathrm{ZOL}$ is generally considered as a safe drug when used for osteoporosis treatment. Acute phase response, which are transient flu like symptoms, has been reported with $\mathrm{ZOL}$ in osteoporotic patients. Its incidence is highest at the first administration and decreases upon subsequent administrations [100].

However, Bps related osteonecrosis of the jaw has been documented in case of administration of high, oncological, dosage of ZOL [101]. Fortunately, the incidence of Bps related osteonecrosis of the jaw in ZOL treated osteoporotic patients is extremely low and is appraised to be less than 1 in 14,200 patient [102].

Cardiac arrhythmia has also been associated with ZOL usage. Atrial fibrillation has also been reported as a possible side effect of ZOL [88]. Moreover, Güzelant et al., 2016, noticed an increased risk of ventricular arrhythmia associated with ZOL administration [103].

Table 1. FDA approved clinical application of zoledronate and alendronate.

\begin{tabular}{cccc}
\hline & Vertebral fracture & Non vertebral fracture & Hip fracture \\
\hline Zoledronate & FDA approved & FDA approved & FDA approved \\
Alendronate & FDA approved & & FDA approved \\
\hline
\end{tabular}




\section{Conclusion}

Bisphosphonates are considered safe drugs, with their benefits in management of postmenopausal osteoporosis outweighing any possible side effects.

\section{References}

[1] Consensus Development Conference on Osteoporosis. Hong Kong, April 1-2, 1993. American Journal of Medicine, 95, 1S-78S.

[2] Kanis, J.A. (2008) Assessment of Osteoporosis at the Primary Health Care Level. WHO Collaborating Centre for Metabolic Bone Diseases, University of Sheffield Medical School; Printed by the University of Sheffield, $6 \mathrm{p}$.

[3] Wright, N.C., Looker, A.C., Saag, K.G. and Jeffrey, R. (2014) The Recent Prevalence of Osteoporosis and Low Bone Mass in the United States Based on Bone Mineral Density at the Femoral Neck or Lumbar Spine. Journal of Bone and Mineral Research, 29, 2520-2526. https://doi.org/10.1002/jbmr.2269

[4] Riggs, B.L. and Melton 3rd, L.J. (1986) Involutional Osteoporosis. The New England Journal of Medicine, 314, 1676-1686. https://doi.org/10.1056/NEJM198606263142605

[5] Melton 3rd, L.J., Thamer, M., Ray, N.F., Chan, J.K., Chesnut 3rd, C.H., Einhorn, T.A., et al. (1997) Fractures Attributable to Osteoporosis: Report from the National Osteoporosis Foundation. Journal of Bone and Mineral Research, 12, 16-23. https://doi.org/10.1359/jbmr.1997.12.1.16

[6] Genant, H., Cooper, C., Poor, G. and Reid, I.R. (1999) Interim Report and Recommendations of the World Health Organization Task-Force for Osteoporosis. Osteoporosis International, 10, 259-264. https://doi.org/10.1007/s001980050224

[7] Chung, H.Y., Sung, B., Jung, K.J., Zou, Y. and Yu, B.P. (2006) The Molecular Inflammatory Process in Aging. Antioxidants \& Redox Signaling, 8, 572-581. https://doi.org/10.1089/ars.2006.8.572

[8] Rivadeneira, F., Styrkarsdottir, U., Estrada, K., Halldorsson, B.V., Hsu, Y.-H., Richards, J.B., et al. (2009) Twenty Bone-Mineral-Density Loci Identified by Large-Scale Meta-Analysis of Genome-Wide Association Studies. Nature Genetics, 41, 1199-1206. https://doi.org/10.1038/ng.446

[9] Shabestari, M. and Eriksen, E.F. (2013) Mechanisms of Bone Remodeling. In: Stovall, D.W., Ed., Osteoporosis, John Wiley \& Sons, Ltd., Hoboken, 31-45. https://doi.org/10.1002/9781118316290.ch3

[10] Lindsay, R., Hart, D.M., Forrest, C. and Baird, C. (1980) Prevention of Spinal Osteoporosis in Oophorectomised Women. Lancet, 2, 1151-1154. https://doi.org/10.1016/S0140-6736(80)92592-1

[11] Recker, R.R., Kimmel, D.B., Parfitt, A.M., Davies, K.M., Keshawarz, N. and Hinders, S. (1988) Static and Tetracycline-Based Bone Histomorphometric Data from 34 Normal Postmenopausal Females. Journal of Bone and Mineral Research, 3, 133-144. https://doi.org/10.1002/jbmr.5650030203

[12] Pacifici, R., Rifas, L., Teitelbaum, S., Slatopolsky, E., McCracken, R., Bergfeld, M., et al. (1987) Spontaneous Release of Interleukin 1 from Human Blood Monocytes Reflects Bone Formation in Idiopathic Osteoporosis. Proceedings of the National Academy of Sciences of the United States of America, 84, 4616-4620. https://doi.org/10.1073/pnas.84.13.4616

[13] Adler, R.A. (2014) Osteoporosis in Men: A Review. Bone Research, 2, Article No. 
14001. https://doi.org/10.1038/boneres.2014.1

[14] Painter, S.E., Kleerekoper, M. and Camacho, P.M. (2006) Secondary Osteoporosis: A Review of the Recent Evidence. Endocrine Practice, 12, 436-445.

[15] Fitzpatrick, L.A. (2002) Secondary Causes of Osteoporosis. Mayo Clinic Proceedings, 77, 453-468. https://doi.org/10.1016/S0025-6196(11)62214-3

[16] Montagnani, A. (2014) Bone Anabolics in Osteoporosis: Actuality and Perspectives. World Journal of Orthopedics, 5, 247-254. https://doi.org/10.5312/wjo.v5.i3.247

[17] Srivastava, M. and Deal, C. (2002) Osteoporosis in Elderly: Prevention and Treatment. Clinics in Geriatric Medicine, 18, 529-555. https://doi.org/10.1016/S0749-0690(02)00022-8

[18] Ivanova, S., Vasileva, L., Ivanova, S., Peikova, L. and Obreshkova, D. (2015) Osteoporosis: Therapeutic Options. Folia Medica, 57, 181-190.

[19] Watts, N.B. and Diab, D.L. (2010) Long-Term Use of Bisphosphonates in Osteoporosis. The Journal of Clinical Endocrinology \& Metabolism, 95, 1555-1565. https://doi.org/10.1210/jc.2009-1947

[20] Ebetino, F.H., Hogan, A.-M.L., Sun, S., Tsoumpra, M.K., Duan, X., Triffitt, J.T., et al. (2011) The Relationship between the Chemistry and Biological Activity of the Bisphosphonates. Bone, 49, 20-33. https://doi.org/10.1016/j.bone.2011.03.774

[21] Graham, R. and Russell, G. (2011) Bisphosphonates: The First 40 Years. Bone, 49, 2-19. https://doi.org/10.1016/j.bone.2011.04.022

[22] Powles, T., Paterson, A., McCloskey, E., Schein, P., Scheffler, B., Tidy, A., et al. (2006) Reduction in Bone Relapse and Improved Survival with Oral Clodronate for Adjuvant Treatment of Operable Breast Cancer. Breast Cancer Research, 8, R13. https://doi.org/10.1186/bcr1384

[23] Miller, P.D. and Watts, N.B. (2013) Bisphosphonates. In: Stovall, D.W., Ed., Osteoporosis: Diagnosis and Management, John Wiley \& Sons, Ltd., Hoboken, 123-143. https://doi.org/10.1002/9781118316290.ch9

[24] Giger, E.V., Castagner, B. and Leroux, J.-C. (2013) Biomedical Applications of Bisphosphonates. Journal of Controlled Release, 167, 175-188. https://doi.org/10.1016/j.jconrel.2013.01.032

[25] Ezra, A. and Golomb, G. (2000) Administration Routes and Delivery Systems of Bisphosphonates for the Treatment of Bone Resorption. Advanced Drug Delivery Reviews, 42, 175-195. https://doi.org/10.1016/S0169-409X(00)00061-2

[26] Dunn, C.J. and Goa, K.L. (2001) Risedronate: A Review of Its Pharmacological Properties and Clinical Use in Resorptive Bone Disease. Drugs, 61, 685-712. https://doi.org/10.2165/00003495-200161050-00013

[27] Roemer-Becuwe, C., Vigano, A., Romano, F., Neumann, C., Hanson, J., Quan, H.K., et al. (2003) Safety of Subcutaneous Clodronate and Efficacy in Hypercalcemia of Malignancy: A Novel Route of Administration. Journal of Pain and Symptom Management, 26, 843-848. https://doi.org/10.1016/S0885-3924(03)00252-5

[28] Rogers, M.J., Crockett, J.C., Coxon, F.P. and Monkkonen, J. (2011) Biochemical and Molecular Mechanisms of Action of Bisphosphonates. Bone, 49, 34-41. https://doi.org/10.1016/j.bone.2010.11.008

[29] Cremers, S. and Papapoulos, S. (2011) Pharmacology of Bisphosphonates. Bone, 49, 42-49. https://doi.org/10.1016/j.bone.2011.01.014

[30] Russell, R.G., Watts, N.B., Ebetino, F.H. and Rogers, M.J. (2008) Mechanisms of Action of Bisphosphonates: Similarities and Differences and Their Potential Influ- 
ence on Clinical Efficacy. Osteoporosis International, 19, 733-759.

https://doi.org/10.1007/s00198-007-0540-8

[31] Drake, M.T. and Cremers, S.C.L.M. (2010) Bisphosphonate Therapeutics in Bone Disease: The Hard and Soft Data on Osteoclast Inhibition. Molecular Interventions, 10, 141-152. https://doi.org/10.1124/mi.10.3.5

[32] Khan, S.A., Kanis, J.A., Vasikaran, S., Kline, W.F., Matuszewski, B.K., McCloskey, E.V., et al. (1997) Elimination and Biochemical Responses to Intravenous Alendronate in Postmenopausal Osteoporosis. Journal of Bone and Mineral Research, 12, 1700-1707. https://doi.org/10.1359/jbmr.1997.12.10.1700

[33] Russell, R.G., Muhlbauer, R.C., Bisaz, S., Williams, D.A. and Fleisch, H. (1970) The Influence of Pyrophosphate, Condensed Phosphates, Phosphonates and Other Phosphate Compounds on the Dissolution of Hydroxyapatite in Vitro and on Bone Resorption Induced by Parathyroid Hormone in Tissue Culture and in Thyroparathyroidectomised Rats. Calcified Tissue Research, 6, 183-196.

https://doi.org/10.1007/BF02196199

[34] Roelofs, A.J., Coxon, F.P., Ebetino, F.H., Lundy, M.W., Henneman, Z.J., Nancollas, G.H., et al. (2010) Fluorescent Risedronate Analogues Reveal Bisphosphonate Uptake by Bone Marrow Monocytes and Localization around Osteocytes in Vivo. Journal of Bone and Mineral Research, 25, 606-616.

https://doi.org/10.1359/jbmr.091009

[35] Coxon, F.P., Thompson, K., Roelofs, A.J., Ebetino, F.H. and Rogers, M.J. (2008) Visualizing Mineral Binding and Uptake of Bisphosphonate by Osteoclasts and Non-Resorbing Cells. Bone, 42, 848-860. https://doi.org/10.1016/j.bone.2007.12.225

[36] Rogers, M.J., Frith, J.C., Luckman, S.P., Coxon, F.P., Benford, H.L., Monkkonen, J., et al. (1999) Molecular Mechanisms of Action of Bisphosphonates. Bone, 24, 73S-79S. https://doi.org/10.1016/S8756-3282(99)00070-8

[37] Bellido, T. and Plotkin, L.I. (2011) Novel Actions of Bisphosphonates in Bone: Preservation of Osteoblast and Osteocyte Viability. Bone, 49, 50-55. https://doi.org/10.1016/j.bone.2010.08.008

[38] Frith, J.C., Monkkonen, J., Auriola, S., Monkkonen, H. and Rogers, M.J. (2001) The Molecular Mechanism of Action of the Antiresorptive and Antiinflammatory Drug Clodronate: Evidence for the Formation in Vivo of a Metabolite That Inhibits Bone Resorption and Causes Osteoclast and Macrophage Apoptosis. Arthritis \& Rheumatology, 44, 2201-2210. https://doi.org/10.1002/1529-0131(200109)44:9<2201::AID-ART374>3.0.CO;2-E

[39] Hiroi-Furuya, E., Kameda, T., Hiura, K., Mano, H., Miyazawa, K., Nakamaru, Y., et al. (1999) Etidronate (EHDP) Inhibits Osteoclastic-Bone Resorption, Promotes Apoptosis and Disrupts Actin Rings in Isolate-Mature Osteoclasts. Calcified Tissue International, 64, 219-223. https://doi.org/10.1007/s002239900606

[40] Sato, M. and Grasser, W. (1990) Effects of Bisphosphonates on Isolated Rat Osteoclasts as Examined by Reflected Light Microscopy. Journal of Bone and Mineral Research, 5, 31-40. https://doi.org/10.1002/jbmr.5650050107

[41] Coxon, F.P., Helfrich, M.H., Larijani, B., Muzylak, M., Dunford, J.E., Marshall, D., et al. (2001) Identification of a Novel Phosphonocarboxylate Inhibitor of Rab Geranylgeranyl Transferase That Specifically Prevents Rab Prenylation in Osteoclasts and Macrophages. The Journal of Biological Chemistry, 276, 48213-48222. https://doi.org/10.1074/jbc.M106473200

[42] Zhang, F.L. and Casey, P.J. (1996) Protein Prenylation: Molecular Mechanisms and Functional Consequences. Annual Review of Biochemistry, 65, 241-269. 
https://doi.org/10.1146/annurev.bi.65.070196.001325

[43] Dunford, J.E., Thompson, K., Coxon, F.P., Luckman, S.P., Hahn, F.M., Poulter, C.D., et al. (2001) Structure-Activity Relationships for Inhibition of Farnesyl Diphosphate Synthase in Vitro and Inhibition of Bone Resorption in Vivo by Nitrogen-Containing Bisphosphonates. Journal of Pharmacology and Experimental Therapeutics, 296, 235-242.

[44] Coxon, F.P. and Rogers, M.J. (2003) The Role of Prenylated Small GTP-Binding Proteins in the Regulation of Osteoclast Function. Calcified Tissue International, 72, 80-84. https://doi.org/10.1007/s00223-002-2017-2

[45] Bergstrom, J.D., Bostedor, R.G., Masarachia, P.J., Reszka, A.A. and Rodan, G. (2000) Alendronate Is a Specific, Nanomolar Inhibitor of Farnesyl Diphosphate Synthase. Archives of Biochemistry and Biophysics, 373, 231-241. https://doi.org/10.1006/abbi.1999.1502

[46] Plotkin, L.I., Weinstein, R.S., Parfitt, A.M., Roberson, P.K., Manolagas, S.C. and Bellido, T. (1999) Prevention of Osteocyte and Osteoblast Apoptosis by Bisphosphonates and Calcitonin. The Journal of Clinical Investigation, 104, 1363-1374. https://doi.org/10.1172/JCI6800

[47] Abe, Y., Kawakami, A., Nakashima, T., Ejima, E., Fujiyama, K., Kiriyama, T., et al. (2000) Etidronate Inhibits Human Osteoblast Apoptosis by Inhibition of Pro-Apoptotic Factor(s) Produced by Activated T Cells. Journal of Laboratory and Clinical Medicine, 136, 344-354. https://doi.org/10.1067/mlc.2000.109757

[48] Plotkin, L.I., Lezcano, V., Thostenson, J., Weinstein, R.S., Manolagas, S.C. and Bellido, T. (2008) Connexin 43 Is Required for the Anti-Apoptotic Effect of Bisphosphonates on Osteocytes and Osteoblasts in Vivo. Journal of Bone and Mineral Research, 23, 1712-1721. https://doi.org/10.1359/jbmr.080617

[49] Fromigue, O. and Body, J.J. (2002) Bisphosphonates Influence the Proliferation and the Maturation of Normal Human Osteoblasts. Journal of Endocrinological Investigation, 25, 539-546. https://doi.org/10.1007/BF03345497

[50] Frediani, B., Spreafico, A., Capperucci, C., Chellini, F., Gambera, D., Ferrata, P., et al. (2004) Long-Term Effects of Neridronate on Human Osteoblastic Cell Cultures. Bone, 35, 859-869. https://doi.org/10.1016/j.bone.2004.06.001

[51] Nishikawa, M., Akatsu, T., Katayama, Y., Yasutomo, Y., Kado, S., Kugal, N., et al. (1996) Bisphosphonates Act on Osteoblastic Cells and Inhibit Osteoclast Formation in Mouse Marrow Cultures. Bone, 18, 9-14. https://doi.org/10.1016/8756-3282(95)00426-2

[52] Viereck, V., Emons, G., Lauck, V., Frosch, K.-H., Blaschke, S., Grundker, C., et al. (2002) Bisphosphonates Pamidronate and Zoledronic Acid Stimulate Osteoprotegerin Production by Primary Human Osteoblasts. Biochemical and Biophysical Research Communications, 291, 680-686. https://doi.org/10.1006/bbrc.2002.6510

[53] Pan, B., Farrugia, A.N., To, L.B., Findlay, D.M., Green, J., Lynch, K., et al. (2004) The Nitrogen-Containing Bisphosphonate, Zoledronic Acid, Influences RANKL Expression in Human Osteoblast-Like Cells by Activating TNF-Alpha Converting Enzyme (TACE). Journal of Bone and Mineral Research, 19, 147-154. https://doi.org/10.1359/jbmr.2004.19.1.147

[54] Nanci, A. (2013) Ten Cate's Oral Histology: Development, Structure and Function. 8th Edition, Elsevier Mosby, St Louis, 81-83.

[55] Khosla, S., Burr, D., Cauley, J., Dempster, D.W., Ebeling, P.R., Felsenberg, D., et al. (2007) Bisphosphonate-Associated Osteonecrosis of the Jaw: Report of a Task Force of the American Society for Bone and Mineral Research. Journal of Bone and Min- 
eral Research, 22, 1479-1491. https://doi.org/10.1359/jbmr.0707onj

[56] Ruggiero, S.L., Mehrotra, B., Rosenberg, T.J. and Engroff, S.L. (2004) Osteonecrosis of the Jaws Associated with the Use of Bisphosphonates: A Review of 63 Cases. Journal of Oral and Maxillofacial Surgery, 62, 527-534. https://doi.org/10.1016/j.joms.2004.02.004

[57] Sharma, D., Ivanovski, S., Slevin, M., Hamlet, S., Pop, T.S., Brinzaniuc, K., et al. (2013) Bisphosphonate-Related Osteonecrosis of Jaw (BRONJ): Diagnostic Criteria and Possible Pathogenic Mechanisms of an Unexpected Anti-Angiogenic Side Effect. Vascular Cell, 5, 1. https://doi.org/10.1186/2045-824X-5-1

[58] Tsao, C., Darby, I., Ebeling, P.R., Walsh, K., O’Brien-Simpson, N., Reynolds, E., et al. (2013) Oral Health Risk Factors for Bisphosphonate-Associated Jaw Osteonecrosis. Journal of Oral and Maxillofacial Surgery, 71, 1360-1366.

https://doi.org/10.1016/j.joms.2013.02.016

[59] Barasch, A., Cunha-Cruz, J., Curro, F., DeRouen, T., Gilbert, G.H., Hujoel, P., et al. (2013) Dental Risk Factors for Osteonecrosis of the Jaws: A CONDOR Case-Control Study. Clinical Oral Investigations, 17, 1839-1845.

https://doi.org/10.1007/s00784-012-0880-4

[60] Khan, A.A., Morrison, A., Hanley, D.A., Felsenberg, D., McCauley, L.K., O’Ryan, F., et al. (2015) Diagnosis and Management of Osteonecrosis of the Jaw: A Systematic Review and International Consensus. Journal of Bone and Mineral Research, 30, 3-23. https://doi.org/10.1002/jbmr.2405

[61] Cartsos, V.M., Zhu, S. and Zavras, A.I. (2008) Bisphosphonate Use and the Risk of Adverse Jaw Outcomes: A Medical Claims Study of 714,217 People. The Journal of the American Dental Association, 139, 23-30. https://doi.org/10.14219/jada.archive.2008.0016

[62] Reid, I.R. (2009) Osteonecrosis of the Jaw: Who Gets It, and Why? Bone, 44, 4-10. https://doi.org/10.1016/j.bone.2008.09.012

[63] Odvina, C.V., Levy, S., Rao, S., Zerwekh, J.E. and Rao, D.S. (2010) Unusual Mid-Shaft Fractures during Long-Term Bisphosphonate Therapy. Clinical Endocrinology, 72, 161-168. https://doi.org/10.1111/j.1365-2265.2009.03581.x

[64] Mashiba, T., Turner, C.H., Hirano, T., Forwood, M.R., Johnston, C.C. and Burr, D.B. (2001) Effects of Suppressed Bone Turnover by Bisphosphonates on Microdamage Accumulation and Biomechanical Properties in Clinically Relevant Skeletal Sites in Beagles. Bone, 28, 524-531. https://doi.org/10.1016/S8756-3282(01)00414-8

[65] Allen, M.R., Iwata, K., Phipps, R. and Burr, D.B. (2006) Alterations in Canine Vertebral Bone Turnover, Microdamage Accumulation, and Biomechanical Properties Following 1-Year Treatment with Clinical Treatment Doses of Risedronate or Alendronate. Bone, 39, 872-879. https://doi.org/10.1016/j.bone.2006.04.028

[66] Nancollas, G.H., Tang, R., Phipps, R.J., Henneman, Z., Gulde, S. and Wu, W. (2006) Novel Insights into Actions of Bisphosphonates on Bone: Differences in Interactions with Hydroxyapatite. Bone, 38, 617-627.

https://doi.org/10.1016/j.bone.2005.05.003

[67] Schnitzer, T., Bone, H.G., Crepaldi, G., Adami, S., McClung, M., Kiel, D., et al. (2000) Therapeutic Equivalence of Alendronate $70 \mathrm{mg}$ Once-Weekly and Alendronate $10 \mathrm{mg}$ Daily in the Treatment of Osteoporosis. Alendronate Once-Weekly Study Group. Aging, 12, 1-12.

[68] Ralston, S. (2015) Bisphosphonates for Osteoporosis. In: Harrison-Woolrych, M., Ed., Medicines for Women, 2015th Edition, Springer International Publishing, Cham, 345-371. https://doi.org/10.1007/978-3-319-12406-3_12 
[69] Mackay Lvwilton, F.J., Pearce, G.L., Freemantle, S.N. and Mann, R.D. (1998) United Kingdom Experience with Alendronate and Oesophageal Reactions. British Journal of General Practice, 48, 1161-1162.

[70] Black, D.M., Reiss, T.E., Nevitt, M.C., Cautey, J., Karpf, D. and Cummings, S.R. (1993) Design of the Fracture Intervention Trial. Osteoporosis International, 3, 29-39. https://doi.org/10.1007/BF01623005

[71] Black, D.M., Cummings, S.R., Karpf, D.B., Cauley, J.A., Thompson, D.E., Nevitt, M.C., et al. (1996) Randomised Trial of Effect of Alendronate on Risk of Fracture in Women with Existing Vertebral Fractures. The Lancet, 348, 1535-1541. https://doi.org/10.1016/S0140-6736(96)07088-2

[72] Cummings, S.R., Black, D.M., Thompson, D.E., Applegate, W.B., Barrett-Connor, E., Musliner, T.A., et al. (1998) Effect of Alendronate on Risk of Fracture in Women with Low Bone Density but without Vertebral Fractures Results from the Fracture Intervention Trial. JAMA, 280, 2077-2082. https://doi.org/10.1001/jama.280.24.2077

[73] Black, D.M., Thompson, D.E., Bauer, D.C., Ensrud, K., Musliner, T., Hochberg, M.C., et al. (2000) Fracture Risk Reduction with Alendronate in Women with Osteoporosis: The Fracture Intervention Trial. JCEM, 85, 4118-4124.

[74] Hochberg, M.C., Ross, P.D., Black, D., Cummings, S.R., Genant, H.K., Nevitt, M.C., et al. (1999) Larger Increases in Bone Mineral Density during Alendronate Therapy Are Associated with a Lower Risk of New Vertebral Fractures in Women with Postmenopausal Osteoporosis. Arthritis \& Rheumatology, 42, 1246-1254. https://doi.org/10.1002/1529-0131(199906)42:6<1246::AID-ANR22>3.0.CO;2-U

[75] Black, D.M., Schwartz, A.V., Ensrud, K.E., et al. (2006) Effects of Continuing or Stopping Alendronate after 5 Years of Treatment. The Fracture Intervention Trial Long-Term Extension (FLEX): A Randomized Trial. JAMA, 296, 2927-2938. https://doi.org/10.1001/jama.296.24.2927

[76] Tucci, J.R., Tonino, R.P., Emkey, R.D., Peverly, C.A., Kher, U., Ii, A.C.S., et al. (1996) Effect of Three Years of Oral Alendronate Treatment Postmenopausal in Women with Osteoporosis. The American Journal of Medicine, 101, 488-501. https://doi.org/10.1016/S0002-9343(96)00282-3

[77] Liberman, U.A., Weiss, S.R., Bröll, J., Minne, H.W., Quan, H., Bell, N.H., et al. (1995) Effect of Oral Alendronate on Bone Mineral Density and the Incidence of Fractures in Postmenopausal Osteoporosis. The New England Journal of Medicine, 333, 1437-1443. https://doi.org/10.1056/NEJM199511303332201

[78] Favus, M., Emkey, R., Leite, M., Devogelaer, J.P., Rodriguez, J., Peverly, C., Kaur, S.A. (1997) Five-Year Treatment of Osteoporosis in Postmenopausal Women with Oral Alendronate: Effects on Bone Mass and Turnover and Safety. Journal of Bone and Mineral Research, 12, 189.

[79] Tonino, R.P., Meunier, P.J., Emkey, R., Rodriguez-Portales, J.A., Menkes, C., Wasnich, R.D., et al. (2000) Skeletal Benefits of Alendronate: 7-Year Treatment of Postmenopausal Osteoporotic Women. The Journal of Clinical Endocrinology \& Metabolism, 85, 3109-3115. https://doi.org/10.1210/jc.85.9.3109

[80] Tucci, J.R., Emkey, R.D., Tonino, R.P., Rodriguez-Portales, J.A., Downs, R.W., Gupta, J., et al. (2004) Ten Years' Experience with Alendronate for Osteoporosis in Postmenopausal Women. The New England Journal of Medicine, 350, 1189-1199.

[81] Cranney, A.N.N., Wells, G., Willan, A., Griffith, L., Zytaruk, N., Robinson, V., et al. (2002) II. Meta-Analysis of Alendronate for the Treatment of Postmenopausal Women. Endocrine Reviews, 23, 508-516. https://doi.org/10.1210/er.2001-2002 
[82] Papapoulos, S.E., Quandt, S.A., Liberman, U.A., Hochberg, M.C. and Thompson, D.E. (2005) Meta-Analysis of the Efficacy of Alendronate for the Prevention of Hip Fractures in Postmenopausal Women. Osteoporosis International, 16, 468-474. https://doi.org/10.1007/s00198-004-1725-Z

[83] Woo, S.-B., Hellstein, J.W. and Kalmar, J.R. (2006) Narrative Review: Bisphosphonates and Osteonecrosis of the Jaws. Annals of Internal Medicine, 144, 753-761. https://doi.org/10.7326/0003-4819-144-10-200605160-00009

[84] Schilcher, J., Michaelsson, K. and Aspenberg, P. (2011) Bisphosphonate Use and Atypical Fractures of the Femoral Shaft. The New England Journal of Medicine, 364, 1728-1737. https://doi.org/10.1056/NEJMoa1010650

[85] Leu, C., Luegmayr, E., Freedman, L.P., Rodan, G.A. and Reszka, A.A. (2006) Relative Binding Affinities of Bisphosphonates for Human Bone and Relationship to Antiresorptive Efficacy. Bone, 38, 628-636.

https://doi.org/10.1016/j.bone.2005.07.023

[86] Gasser, J.A., Ingold, P., Venturiere, A., Shen, V. and Green, J.R. (2008) Long-Term Protective Effects of Zoledronic Acid on Cancellous and Cortical Bone in the Ovariectomized Rat. Journal of Bone and Mineral Research, 23, 544-551.

https://doi.org/10.1359/jbmr.071207

[87] Grey, A., Bolland, M., Wattie, D., Horne, A., Gamble, G. and Reid, I.R. (2010) Prolonged Antiresorptive Activity of Zoledronate. Journal of Bone and Mineral Research, 25, 2251-2255. https://doi.org/10.1002/jbmr.103

[88] Black, D.M., Delmas, P.D., Eastell, R., Reid, I.R., Boonen, S., Cauley, J.A., et al. (2007) Once-Yearly Zoledronic Acid for Treatment of Postmenopausal Osteoporosis. The New England Journal of Medicine, 356, 1809-1822. https://doi.org/10.1056/NEJMoa067312

[89] Recker, R.R., Delmas, P.D., Halse, J., Reid, I.R., Boonen, S., García-Hernandez, P.A., et al. (2008) Effects of Intravenous Zoledronic Acid Once Yearly on Bone Remodeling and Bone Structure. Journal of Bone and Mineral Research, 23, 6-16. https://doi.org/10.1359/jbmr.070906

[90] Delmas, P.D., Munoz, F., Black, D.M., Cosman, F., Boonen, S., Watts, N.B., et al. (2009) Effects of Yearly Zoledronic Acid $5 \mathrm{mg}$ on Bone Turnover Markers and Relation of PINP with Fracture Reduction in Postmenopausal Women with Osteoporosis. Journal of Bone and Mineral Research, 24, 1544-1551. https://doi.org/10.1359/jbmr.090310

[91] Black, D.M., Reid, I.R., Boonen, S., Bucci-Rechtweg, C., Cauley, J.A., Cosman, F., et al. (2012) The Effect of 3 versus 6 Years of Zoledronic Acid Treatment of Osteoporosis: A Randomized Extension to the Horizon-Pivotal Fracture Trial (PFT). Journal of Bone and Mineral Research, 27, 243-254. https://doi.org/10.1002/jbmr.1494

[92] Cosman, F., Cauley, J.A., Eastell, R., Boonen, S., Palermo, L., Reid, I.R., et al. (2014) Reassessment of Fracture Risk in Women after 3 Years of Treatment with Zoledronic Acid: When Is It Reasonable to Discontinue Treatment? The Journal of Clinical Endocrinology \& Metabolism, 99, 4546-4554. https://doi.org/10.1210/jc.2014-1971

[93] Black, D.M., Reid, I.R., Cauley, J.A., Cosman, F., Leung, P.C., Lakatos, P., et al. (2015) The Effect of 6 versus 9 Years of Zoledronic Acid Treatment in Osteoporosis: A Randomized Secondextension to the Horizon-Pivotal Fracture Trial (PFT). American Society for Bone and Mineral Research, 30, 934-944. https://doi.org/10.1002/jbmr.2442

[94] Grey, A., Bolland, M.J., Wattie, D., Horne, A., Gamble, G. and Reid, I.R. (2009) The 
Antiresorptive Effects of a Single Dose of Zoledronate Persist for Two Years: A Randomized, Placebo-Controlled Trial in Osteopenic Postmenopausal Women. The Journal of Clinical Endocrinology \& Metabolism, 94, 538-544. https://doi.org/10.1210/jc.2008-2241

[95] Greenspan, S.L., Perera, S., Ferchak, M.A., Nace, D.A. and Resnick, N.M. (2015) Efficacy and Safety of Single-Dose Zoledronic Acid for Osteoporosis in Frail Elderly Women a Randomized Clinical Trial. Journal of the American Medical Association, 175, 913-921.

[96] Boonen, S., Kaufman, J.-M., Lippuner, K., Zanchetta, J., Langdahl, B., Rizzoli, R., et al. (2012) Fracture Risk and Zoledronic Acid Therapy in Men with Osteoporosis. The New England Journal of Medicine, 367, 1714-1732. https://doi.org/10.1056/NEJMoa1204061

[97] Lekamwasam, S., Adachi, J.D., Agnusdei, D., Bilezikian, J., Boonen, S., Borgström, F., et al. (2012) A Framework for the Development of Guidelines for the Management of Glucocorticoid-Induced Osteoporosis. Osteoporosis International, 23, 2257-2276. https://doi.org/10.1007/s00198-012-1958-1

[98] Wellington, K., Goa, K.L., Coleman, R.E., Dearnaley, D.R., Fleisch, H. and Hotte, S.J. (2003) Zoledronic Acid: A Review of Its Use in the Management of Bone Metastases and Hypercalcaemia of Malignancy. Drugs, 63, 417-437.

https://doi.org/10.2165/00003495-200363040-00009

[99] Wood, J., Bonjean, K., Ruetz, S., Ene, A.B., Devy, L., Foidart, J.M., et al. (2002) Novel Antiangiogenic Effects of the Bisphosphonate Compound Zoledronic Acid. Journal of Pharmacology and Experimental Therapeutics, 302, 1055-1061. https://doi.org/10.1124/jpet.102.035295

[100] Reid, I.R., Gamble, G.D., Mesenbrink, P., Lakatos, P. and Black, D.M. (2010) Characterization of and Risk Factors for the Acute-Phase Response after Zoledronic Acid. The Journal of Clinical Endocrinology \& Metabolism, 95, 4380-4387. https://doi.org/10.1210/jc.2010-0597

[101] Rathbone, E.J., Brown, J.E., Marshall, H.C., Collinson, M., Liversedge, V., Murden, G.A., et al. (2013) Osteonecrosis of the Jaw and Oral Health-Related Quality of Life after Adjuvant Zoledronic Acid: An Adjuvant Zoledronic Acid to Reduce Recurrence Trial Subprotocol (BIG01/04). Journal of Clinical Oncology, 31, 2685-2691. https://doi.org/10.1200/JCO.2012.46.4792

[102] Grbic, J.T., Black, D.M., Lyles, K.W., Reid, D.M., Orwoll, E., McClung, M., et al. (2010) The Incidence of Osteonecrosis of the Jaw in Patients Receiving 5 Milligrams of Zoledronic Acid: Data from the Health Outcomes and Reduced Incidence with Zoledronic Acid Once Yearly Clinical Trials Program. The Journal of the American Dental Association, 141, 1365-1370. https://doi.org/10.14219/jada.archive.2010.0082

[103] Güzelant, A.Y., Sarıfakıoğlu, A.B., Yılmaz, I., Alpsoy, Ş., Saraçoğlu, G.V. and Taşdemir, N. (2016) Should the Cardiac Rhythm Be Monitored Following Administration of Zoledronic Acid in Elderly Osteoporotic Women? Turkish Journal of Physical Medicine and Rehabilitation, 62, 214-221. 


\section{List of Abbreviation}

\begin{tabular}{cc}
\hline Word & Abbreviation \\
\hline Receptor activator of nuclear factor kabba beta ligand & RANKL \\
Receptor activator of nuclear factor kabba beta & RANK \\
Osteoprotegerin & OPG \\
Adenosine triphosphate & ATP \\
guanosine tri phosphatases & GTPases \\
Hydroxy apatite & HA \\
Bisphosphonates & BPs \\
Nitrogen bisphosphonates & N-BPs \\
Zoledronic acid & ZOL \\
Bone mineral density & BMD
\end{tabular}

